\title{
Vascular health in children and adolescents: effects of obesity and diabetes
}

\author{
This article was published in the following Dove Press journal: \\ Vascular Health and Risk Management \\ 9 November 2009 \\ Number of times this article has been viewed
}

\author{
Kevin R Short \\ Piers R Blackett \\ Andrew W Gardner \\ Kenneth C Copeland \\ Department of Pediatrics, Section \\ of Diabetes and Endocrinology, \\ University of Oklahoma Health \\ Sciences Center, Oklahoma City, \\ OK, USA
}

Correspondence: Kenneth C Copeland I 200 N. Phillips, Suite 4500,

Oklahoma City, OK 73104-4600, USA

$\mathrm{Tel}+$ I 405 27| 6764

Fax + I $40527 \mid 3093$

Email kenneth-copeland@ouhsc.edu

\begin{abstract}
The foundations for cardiovascular disease in adults are laid in childhood and accelerated by the presence of comorbid conditions, such as obesity, diabetes, hypertension, and dyslipidemia. Early detection of vascular dysfunction is an important clinical objective to identify those at risk for subsequent cardiovascular morbidity and events, and to initiate behavioral and medical interventions to reduce risk. Typically, cardiovascular screening is recommended for young adults, especially in people with a family history of cardiovascular conditions. Children and adolescents were once considered to be at low risk, but with the growing health concerns related to sedentary lifestyle, poor diet and obesity, cardiovascular screening may be needed earlier so that interventions to improve cardiovascular health can be initiated. This review describes comorbid conditions that increase cardiovascular risk in youth, namely obesity and diabetes, and describes noninvasive methods to objectively detect vascular disease and quantify vascular function and structure through measurements of endothelial function, arterial compliance, and intima-media thickness. Additionally, current strategies directed toward prevention of vascular disease in these populations, including exercise, dietary interventions and pharmacological therapy are described.
\end{abstract}

Keywords: endothelial function, arterial compliance, intimal medial thickness, inflammation, intervention

\section{Introduction}

The incidence of obesity in US children has increased almost threefold within the last three decades. ${ }^{1}$ With it has come insulin resistance, ${ }^{2}$ and a rarely before seen phenomenon, type 2 diabetes in childhood. ${ }^{1,3,4}$ Public health experts suggest that this early appearance of type 2 diabetes will result in a major societal health burden to the next generation, in large part because of anticipated debilitating cardiovascular comorbidities. Vascular disease in adulthood has been studied extensively with techniques used to assess both vascular function and anatomic pathology. Diabetes is a known risk factor for both micro and macrovascular disease, and the relationships among glycemia, lipid abnormalities, blood pressure control, vascular pathology, and cardiovascular events and mortality in diabetic adults are well described. Less is known about these interactions in children with diabetes, especially those with type 2 diabetes. Recently, preliminary results from the National Institutes of Health (NIH)-supported multicenter TODAY (Treatment Options for type 2 Diabetes in Adolescents and Youth) trial suggested that as many as $60 \%$ of children referred for new onset type 2 diabetes have some form of dyslipidemia, and 17\% have hypertension (defined as a blood pressure greater than the 95th percentile for age, height, and sex). 5,6 These associated 
co-morbidities at or near diagnosis lend credibility to the suggestion that such children are at extremely high risk for developing premature vascular disease. Although vascular pathology in obese and diabetic children has been described, the time course of development of abnormalities in vascular function and anatomic pathology, and relationships among comorbidities are poorly understood.

In adults detectable abnormalities in vascular function typically precede the development of vascular anatomical pathology. ${ }^{7-10}$ Vascular dysfunction, including reduced endothelial function and arterial compliance and increased inflammatory markers, is detectable in obese and diabetic subjects prior the appearance of anatomical abnormalities. ${ }^{8-13}$ This has led to the postulated sequence of events whereby early changes in vascular risk factors such as obesity, hyperlipidemia, hypertension, and impaired glycemia promote initial endothelial dysfunction and stiffness of small vessels. Inflammation and continued presence of these risk factors leads subsequently to atherosclerotic development with altered vascular structure and increased stiffness of the large vessels. ${ }^{10}$

Although children and young adults with familial hyperlipidemia and family history of type 2 diabetes are known to be at increased risk for early development of vascular pathology, ${ }^{14-17}$ less is known about the independent risk factors of obesity and diabetes, and the role of inflammation in the process of vascular pathology development in childhood. Since children rarely develop major cardiovascular complications during childhood, and since type 2 diabetes in childhood is a relatively recent phenomenon, it is not surprising that reports defining pathological vascular function in childhood type 2 diabetes are limited. Components of the metabolic syndrome with or without diabetes are associated with evidence of pathological arterial changes in adolescence measured as the area of fatty streaks and raised plaques in post-mortem studies. ${ }^{18}$ Obese children routinely have been shown to have many of the proinflammatory, proathrogenic changes associated with vascular disease in adults, including insulin resistance, hepatic steatosis, elevated total-, low-density lipoprotein-cholesterol (LDL-C), and oxidized LDL-C, elevated levels of vascular adhesion molecules, tumor necrosis factor- $\alpha$ (TNF- $\alpha$ ), C-reactive protein, interleukin-6 (IL-6), and fibrinogen, while high-density lipoprotein-cholesterol (HDL-C) and adiponectin are reduced. ${ }^{19-28}$ These deleterious changes set the stage of early development of vascular dysfunction and atherosclerosis. Most concerning is the evidence that these risk factors are fairly stable in adolescents if body mass index (BMI) is unchanged ${ }^{29}$ and track from adolescence into adulthood. ${ }^{30}$ Further, risk factors in adolescence predict preathersclerotic changes such as increased carotid intimamedia thickness (IMT) in adulthood. ${ }^{7,11,31,32}$ Thus, while overt atherosclerosis may not be evident in most obese or diabetic children, the predisposition to its development may be underway well before adulthood.

This review summarizes results of commonly used noninvasive techniques for assessing vascular health in children, with recent data for normal patterns of development and aging. In addition this review summarizes evidence that obesity and diabetes in childhood are associated with vascular pathology, including speculation regarding the sequence of events leading to overt cardiovascular disease that occurs typically later in adulthood, and the likelihood of reversibility of pathology following interventions. Finally, we summarize the evidence for current lifestyle and pharmacological management effects on vascular health in children with obesity and type 2 diabetes.

\section{Methodological approaches to assessing vascular function and structure Endothelial function \\ Methods of assessment}

Endothelial function is often measured in adults and children with the noninvasive method of flow-mediated dilation (FMD). The most common method of assessing FMD is to measure the change in brachial arterial diameter in response to brief (five minutes) of arterial occlusion..$^{33-37}$ Flow occlusion is performed with a blood pressure cuff and Doppler ultrasound is used to image the artery diameter during and for up to five minutes after occlusion. ${ }^{37-42}$ Once the cuff is released the resumption of flow creates shear stress on the vascular wall, which stimulates nitric oxide production by the endothelial lining and in turn causes relaxation of vascular smooth muscle..$^{38,40,43}$ The brachial artery typically dilates $\sim 6 \%-12 \%$ in healthy people. ${ }^{40-42,44}$ Following FMD measurement, the endothelial-independent vasodilatory response can be assessed by sublingual administration of gyceryl trinitrate (GTN, nitroglycerin), which relaxes the vascular smooth muscle to cause a further increase in vessel diameter. ${ }^{13,45}$ Jarvisalo and colleagues ${ }^{46}$ reported that FMD and GTN-mediated brachial dilation are positively correlated $(r=0.46)$ in children while another study showed that values from the two methods were similarly reduced in children with obesity or type 1 diabetes compared to nonobese children. ${ }^{19}$ 
Although ultrasound has been the standard approach to measure FMD and associated changes in blood flow, this technique requires skilled operators and expensive instrumentation, and acquiring reproducible results can be challenging. For this reason, results may vary among research sites and application to clinical practice has been limited. ${ }^{33,47}$ Recently, alternative methods that are less operator-dependent have been developed. These techniques utilize the same physiologic principles, and quantify reactive hyperemia as a change in fingertip perfusion pressure measured by tonometry ${ }^{48-50}$ or temperature ${ }^{51,52}$ following brachial arterial occlusion. Both of these fingertip methods have been used to assess differences in clinical populations, including the Framingham Heart Study cohort $^{53,54}$ as well as studies in children. ${ }^{49,50,55}$ Recent work showed that the results of both fingertip methods were positively associated $(r=\sim 0.46)$ with the brachial FMD method in young healthy men..$^{52}$ The finding that these correlation values were not higher might be expected since brachial artery FMD is considered a macrovascular index, whereas the fingertip tonometric and thermal measures might best be considered indices of small vessel (microvasculature) function. Interestingly, though, the digital tonometric results correlate positively with cutaneous reactive hyperemia $(\mathrm{r}=0.55)$, another microvascular measure determined by laser Doppler monitoring of an adjacent finger, while the thermal response method has not been shown to correlate significantly with either tonometry or cutaneous hyperemia. These results suggest that different methodologies may assess separate or partially overlapping physiological components of vascular function and that use of multiple approaches could be potentially useful to obtain complimentary information. ${ }^{52}$

\section{Age-related and developmental changes}

Several studies have demonstrated that endothelial function, measured by FMD, declines with age in adults without cardiovascular disease. ${ }^{56-59}$ The decline in older adults has been reported to be evident in both arm and leg arteries ${ }^{56,59}$ and inversely related to the concentration of LDL-C in sedentary older people. ${ }^{58}$ Although FMD mesurements have been extensively performed on children to assess the effects of various conditions, there are relatively few data on normal developmental patterns of endothelial function. In a study of 105 children aged 9-16 years it was shown that the time course and peak FMD measured after occlusion were inversely associated with arterial diameter and total cholesterol concentration, but not age.$^{60}$ Arterial diameter increases during childhood, indicating the possibility that changes in FMD may be more closely linked to growth and development than to age per se. A recent examination of determinants of FMD values in children and adults ${ }^{57}$ showed that FMD, measured as the percent change in brachial arterial diameter, was highest in children (aged 10 years, 10.7\% FMD) and declined with increasing age in young adults (aged 27 years, $7.5 \%$ ) and middle-aged/older adults (aged 58 years, $6.0 \%$ ). Children had smaller arteries and higher shear stress after occlusion than adults. Adjusting FMD for shear stress eliminated the difference in FMD between children and young adults, while the oldest group remained significantly lower than both younger groups. Nevertheless, shear stress only accounted for $\sim 15 \%$ of the variation in FMD and an association with shear stress was not seen in children as in adults..$^{57}$ These findings suggest that at least some components of endothelial function may be regulated through different mechanisms in children and adults and require further evaluation.

\section{Effects of obesity, diabetes, and other comorbidities}

Numerous reports have described impairments in endothelial function by up to $50 \%$ in obese children and adolescents compared to normal weight peers, similar to findings in obese adults. ${ }^{13,19,20,22,40,41,44,61-65}$ Both endothelial-dependent FMD and endothelial-independent (response to GTN) vasodilatation typically are related inversely to BMI in normal weight children $^{60}$ and are reported to be lower in obese children in some, ${ }^{19,45,65}$ but not all ${ }^{66}$ studies. Several longitudinal prospective studies have shown that endothelial-dependant vasodilation is inversely associated with increased risk of cardiovascular events and death in older adults ${ }^{67,68}$ and in middle-aged adults without apparent heart disease risk. ${ }^{69}$ The endothelial-independent vasodilatory response appears to be less prognostic of disease, particularly in subclinical adult populations. ${ }^{69,70}$ Because the increase in childhood obesity and type 2 diabetes are relatively recent phenomena, and because cardiovascular disease develops over several years, morbidity and mortality data linking endothelial function to cardiovascular events in children are currently unavailable. However, it is likely that development of obesity early in life and sustained into adulthood would increase the risk of cardiovascular events earlier in life.

Beyond the effects of obesity, the presence of other metabolic risk factors has been inversely associated with impaired endothelial function in children, particularly increased concentrations of inflammatory markers, such as C-reactive protein, and total cholesterol or oxidized LDL-C. ${ }^{46,63,71,72}$ Micro- and macrovascular function have been shown to be reduced in adults with impaired glucose tolerance and type 2 diabetes compared to healthy controls ${ }^{73}$ 
but similar data for children with type 2 diabetes are not yet available. Endothelial function is, however, reduced in children with type 1 diabetes, suggesting that glycemic control may be influential. ${ }^{19,49,72,74}$ Since type 2 diabetes is nearly always accompanied by obesity, endothelial function is likely to be reduced in the pediatric type 2 diabetes population, though it will be important to determine if diabetes imposes a further impairment beyond the effect of obesity. In adults with diabetes intensive glucose management is associated with a lower incidence of microvascular complications, ${ }^{76}$ and type 2 diabetic patients who experience large fluctuations in circulating glucose concentrations have even more acute impairment in endothelial function when compared to those with sustained high glucose concentration. ${ }^{75}$ A known risk factor for cardiovascular disease in adults, elevated blood pressure, was reported to be present in $17 \%$ of all obese children and adolescents with type 2 diabetes at screening for entry into the TODAY trial. ${ }^{5,6}$ Elevated blood pressure is encountered more commonly in obese compared to normal weight children, and systolic pressure is inversely associated with endothelial function. ${ }^{19}$ Perhaps even more importantly, elevated blood pressure during adolescence appears to be a predictor of endothelial dysfunction in adulthood. A longitudinal prospective study of 2,109 young Finnish adults showed that systolic pressure measured in boys aged 12-18 years was negatively correlated with FMD scores measured at ages 24-39 years. This relationship was not present for females, nor was there a significant relationship between blood pressure at early ages (3-9 years) and the FMD value measured in early adulthood. ${ }^{77}$ Collectively, these findings suggest that endothelial function is affected adversely affected by the presence of multiple vascular risk factors. However, Mimoun and colleagues ${ }^{78}$ measured FMD and nitroglyceridestimulated brachial artery dilation in 161 obese children and reported that a subset of children who met current definitions for metabolic syndrome had endothelial function measures that were no different from those children without metabolic syndrome. Notably, this study did not report how many of the obese participants had elevated values for one or more components of metabolic syndrome and a normal weight reference group was not included.

\section{Arterial compliance}

Arterial compliance is the amount of arterial expansion and recoil that occurs with cardiac pulsation and relaxation, and is linked to both structural and functional properties of the artery. ${ }^{79}$ There are several noninvasive methods available to measure arterial compliance, including diastolic pulse contour analysis (PCA), pulse wave velocity (PWV), and high-resolution ultrasound.

\section{Methods of assessment}

Diastolic PCA is a widely used method that provides indices of both large and small arterial compliance. ${ }^{80}$ Large artery compliance (capacitive compliance) and small artery compliance (reflective compliance) are calculated through analysis of the decay in the diastolic blood pressure waveforms and reflected waveforms. ${ }^{81}$ An advantage of diastolic PCA is that it allows an assessment of small artery compliance, which provides an index of the microcirculation and endothelial function; this is in contrast to the tonometric determination of carotid or femoral arterial pulse wave velocity that assesses only central and large artery compliance. ${ }^{82}$ Other cardiovascular parameters obtained during waveform collection include blood pressure, pulse rate, systemic vascular resistance, and total vascular impedance. Diastolic PCA measurements of arterial compliance are valid and reliable in adults. ${ }^{83}$

Arterial compliance is also assessed by measuring PWV using pressure tonometers placed at two arterial sites (applanation tonometry, eg, typically radial and carotid), and electrocardiogram-recorded timing of the transit of a pulse pressure wave. Other clinically significant measures that can be obtained from applanation tonometry include the augmentation index, as well as pulse pressures obtained from brachial, aortic, and carotid sites. ${ }^{84}$ Augmentation index and pulse pressure both correlate highly with cardiovascular mortality and events. ${ }^{85,86}$ Ultrasound approaches are used to assess arterial compliance as the change in lumen diameter from diastolic to systolic phases, typically at the carotid artery. ${ }^{87}$ All of the methods used to measure compliance may vary with the site of measurement (central versus peripheral) and must be adjusted for pulse pressure. Care must be taken to standardize measurements to control for several factors that affect the measurements including time of day, smoking, intake of food, caffeine or other stimulants, prior exercise, room temperature, menstrual cycle phase, and mental stress.

\section{Age-related and developmental changes}

In healthy adults, carotid stiffness increases with age, and is positively related to blood pressure and BMI but has not been reported to differ with sex. ${ }^{87}$ Likewise, systemic arterial compliance decreases in adults from the ages of 21-96 years. ${ }^{10,88,89}$ A study by Collins and colleagues, ${ }^{90}$ using the brachial-ankle PWV method suggested that the decline in peripheral large arterial compliance begins in adolescence. As shown in Figure 1, however, Gardner and Parker, ${ }^{91}$ 
recently reported that both large and small arterial elasticity, assesed using radial artery PCA, increase from the age of seven years through adolescence in healthy people, peaking in the early- to mid-20's. That study also showed, in agreement with McVeigh, ${ }^{88}$ that the decline in small artery elasticity during adulthood is of a greater relative magnitude than the change in large artery elasticity. At least part of the age-related decline in adults may be due to the cummulative effect of reduced physical activity as it has been shown that arterial compliance is maintained at youthful levels in older people who exercise regularly. ${ }^{89,92,93}$ The differences in arterial compliance changes during adolescence reported by Gardner
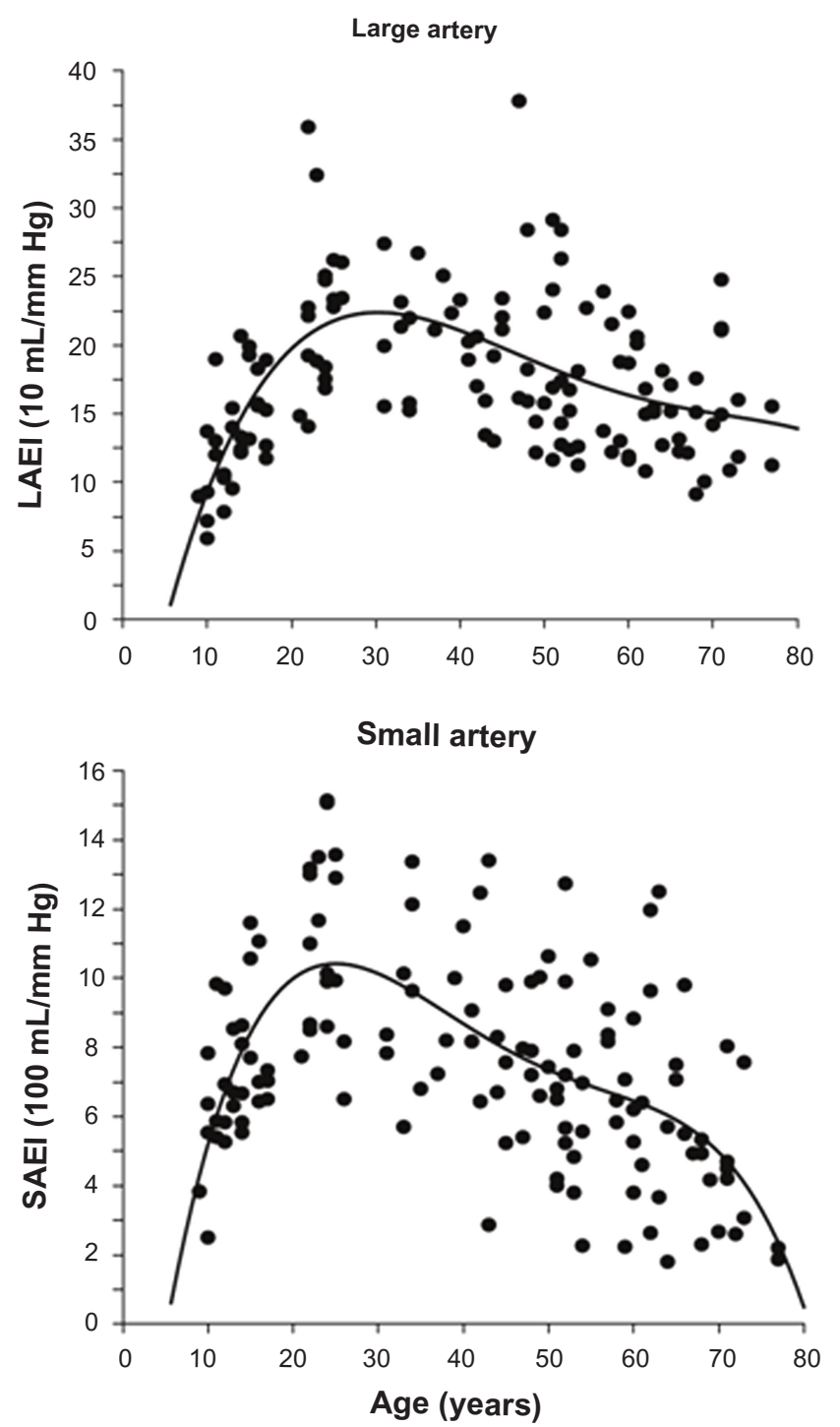

Figure I Changes in large and small arterial elasticity with age in children and adults. Measurements acquired using radial artery tonometry and diastolic pulsewave contour analysis in healthy people across the age span. Adapted with permission from Gardner AW, Parker DE. Association between arterial compliance and age in participants 9 to 77 years old. Angiology. 2009; Jul 27. [Epub ahead of print].

Abbreviations: LAEI, large arterial elastic index; SAEI, small arterial elastic index. and Parker ${ }^{91}$ and Collins and colleagues ${ }^{90}$ may be attributable to variations in the measurment techniques employed, study population, or other factors such as lifestyle. This variation hightlights the need to further define developmental changes in arterial compliance with complimentary approaches.

\section{Effects of obesity, diabetes, and other comorbidities}

As in adulthood, central arterial compliance measured most commonly by PWV, is lower in youth who are obese. Compliance and elasticity of the carotid artery was shown to be impaired in obese children and young adults in some studies, ${ }^{62,94}$ although a recent report on a small number of children did not confirm this finding. ${ }^{66}$ Another recent study of more than 500 Australian school children, average age 10 years, showed that carotid-femoral PWV was positively correlated with BMI and percentage body fat, ${ }^{95}$ supporting the idea that adiposity results in increased stiffness of large arteries even at a young age. In contrast, obese adolescent girls (mean age 14 years) were shown to have lower PWV and higher arterial diameters compared to lean adolescent girls, despite increased radial intimal thickness. ${ }^{96}$ The authors who reported this unexpected result proposed that hyperinsulinemia associated with obesity and relative insulin resistance might stimulate chronic vasorelaxation and higher vascular compliance. Additionally, we suggest that the higher arterial compliance in childhood obesity might indicate developmental change associated with maturation. This hypothesis is in accord with our own data using PCA, which shows increasing arterial small and large vessel compliance in childhood (Figure 1). Since obese children are relatively taller and more sexually mature compared with their normal weight peers, they may have higher arterial compliance throughout childhood than normal weight children before reaching their peak arterial compliance as young adults. Nevertheless, it is clear that more widespread application of these newer assessment methods first will require establishment of age and developmental stage-related norms.

Most of the data available regarding the effect of diabetes on arterial compliance have been reported only in adults. Components of the metabolic syndrome are strongly predictive of reductions in both small and large arterial compliance in adults, with obesity and hypertension having the greatest impact. ${ }^{97-99}$ Adults with either type 1 or type 2 diabetes have reduced arterial compliance compared to nondiabetic subjects. ${ }^{100,101}$ Further, for those with type 2 diabetes, increased arterial stiffness, assessed by aortic PWV, was positively associated with peripheral neuropathy (odds ratio: 1.8) and retinopathy (odds ratio: 3.8), even after 
controlling for several potentially confounding metabolic variables. ${ }^{101} \mathrm{~A}$ familial influence of type 2 diabetes has been shown to impact arterial compliance in early adulthood. At least two studies have shown that either carotid-radial or carotid-femoral PWV is reduced in normoglycemic, normotensive young adults who are offspring of parents with type 2 diabetes when compared to control groups without diabetes family history. ${ }^{15,17}$ The small amount of data available to date indicate that carotid compliance and elasticity are reduced in adolescents and young adults with type 2 diabetes, compared to those measurements in lean nondiabetic peers, but are not different from obese participants without diabetes. ${ }^{94}$ This shows that arterial compliance is impaired in young type 2 diabetic subjects but suggests that diabetes in youth may pose an additional burden on arterial compliance beyond that of obesity. This finding needs to be confirmed and extended, including additional central and peripheral measures of compliance.

Hypertension also correlates closely with arterial compliance. In adults with hypertension, arterial compliance is lower than that of matched controls..$^{97,102,103}$ In young adults (average age 23 years) large and small arterial compliance, assessed with radial artery tonometry, were inversely related to blood pressure over a wide range of blood pressure values. ${ }^{104}$ Similar data in children are limited in this area. In a study of children considered to be at increased cardiovascular risk because of the presence of elevated blood pressure and total cholesterol, carotid elasticity was found to be reduced compared to an age-matched control group. ${ }^{105}$ The at-risk group also had evidence of higher body fat assessed by skinfolds so it remains to be demonstrated which of these variables (blood pressure, lipids, obesity), all of which tend to cluster clinically, contributed to the differences in arterial compliance observed. More recently it was shown that hypertensive children have reduced carotid elasticity, although carotid compliance was higher. ${ }^{106}$ Together the existing data demonstrate that arterial stiffness is increased in adults with obesity, diabetes and hypertension. The limited data available in children tend to support the same conclusion.

\section{Intima-media thickness (IMT)}

\section{Methods of assessment}

Measurement of IMT is performed using high-resolution ultrasonography, most often at the carotid artery, though peripheral sites have also been examined. ${ }^{106-109}$ A skilled operator is required and probe placement must be optimized for each patient to locate stable images of regions of interest. Images typically are collected from the leading edge of the lumen-intima interface on the far wall of the vessel. Visualization of IMT can be challenging because the vessel thickness is small (reported average values in normal and obese children and adults range from $0.34-0.80 \mathrm{~mm}$ ), but differences within comparison groups or in longitudinal studies may only be 10\%-15\% (30-100 $\mu \mathrm{m})$. Differences in technique and measurement site can add to the variability both within and between research groups and test-retest variation within the same participants only a month apart, even when conducted by an experienced group, can be low. ${ }^{110}$ However, use of automated contour identification methods for the analyses can reduce subjective image quantification, and is reported to reduce the variability while increasing the number of measurement points analyzed. ${ }^{111,112}$ There may still be some inherent biological variability related to the choice of measurement location. Urbina and colleagues ${ }^{94}$ recently reported that IMT in the internal carotid was significantly higher in a large group of obese children and young adults (mean age 17.8 years, range 10-24) compared to age- and sex-matched nonobese participants, but did not differ with obesity when measured in the common carotid or at the carotid bulb locations. Despite some of these challenges, collective evidence has shown that IMT increases with age and obesity but is responsive to dietary or exercise interventions lasting at least six months, as subsequently described.

\section{Age-related and developmental changes}

Artery diameter increases with age in children as part of normal development, particularly in the lumen. ${ }^{108,109}$ Whether IMT changes with age is less clear. Some studies show an increase in carotid IMT with age in children ${ }^{108,113}$ while others show little or no change. ${ }^{109,110,114}$ This is likely due to the very small changes that occur and the technical challenges of precise, reliable measurements. Femoral IMT increases with age in children but the changes are also small. ${ }^{108,109}$ Additionally, vessel wall density, particularly in the aorta, has been demonstrated to increase during childhood. ${ }^{115}$ During adulthood vessel size (common carotid) remains stable but the IMT increases, particularly in the presence of cardiovascular risk factors, including obesity. ${ }^{11,57}$

\section{Effects of obesity, diabetes, and other comorbidities}

In adults the presence of increased carotid IMT is associated with an increased risk of cardiovascular events. ${ }^{107,116,117}$ Several studies have reported increased carotid or peripheral IMT in obese prepubertal children and adolescents aged 11-14 years old. ${ }^{21-23,62,66,94,96}$ In those studies, elevated IMT was associated with higher blood pressure, insulin 
resistance or inflammatory markers. In the study by Meyer and colleagues ${ }^{22}$ performed in 14-year-old boys and girls, elevated IMT was also associated with lower brachial FMD. In contrast, another study reported no effect of obesity on carotid IMT in prepubertal children aged 6-11 years, despite the presence of elevated blood pressure and lower brachial FMD in the obese group. ${ }^{13}$ The lack of difference in IMT in that study may be due to the relatively younger developmental age of the participants compared to other investigations. This reflects the challenge of identifying small differences in vascular wall thickness among groups. The finding that a reduction in FMD was evident while a change in IMT was not detected supports the hypothesis that functional changes are likely to precede anatomic changes in vascular health.

One of the best recognized risk factor correlates with IMT in children is blood pressure. In a multivariate analysis of 96 obese boys and girls aged 9-13 years, predictors of carotid IMT included systolic blood pressure, C-reactive protein, BMI, and fasting glucose, with systolic blood pressure contributing the most $(15 \%)$ to the variance in IMT. ${ }^{23}$ Further, increased IMT is often found in children with hypertension. ${ }^{106,118,119}$ The study by Lande and colleages ${ }^{119}$ conducted in 10-18-year-old children confirmed that daytime systolic blood pressure, measured with ambulatory monitoring, was positively correlated $(r=0.57)$ with carotid IMT. Thus, hypertension appears to be key to promoting the vascular remodeling that is commonly seen in obese adolescents.

Metabolic syndrome and diabetes also appear to contribute to increased IMT. In a study of young adults (mean age $\sim 32$ years) without diabetes carotid IMT increased progressively with the number of metabolic syndrome components present. ${ }^{120}$ Consistent with other studies, elevated blood pressure, either systolic $\geq 130$ or diastolic $\geq 85 \mathrm{~mm} \mathrm{Hg}$, was the strongest single predictor of IMT, but low HDL-cholesterol $(<40 \mathrm{mg} / \mathrm{dL})$ was also closely related. Fasting glucose $\geq 110 \mathrm{mg} / \mathrm{dL}$, triglycerides $\geq 150 \mathrm{mg} / \mathrm{dL}$ and waist circumference ( $\geq 102 \mathrm{~cm}$ for men or $\geq 88 \mathrm{~cm}$ for women) contributed progressively less to the variation in IMT. ${ }^{120}$ Likewise, in overweight Latino children (mean age 11 years) who were followed over three years, consistent presence of metabolic syndrome at annual visits was associated with higher carotid IMT compared to those children without metabolic syndrome. ${ }^{121}$ In comparison, in a study of 161 obese children, IMT, FMD, and arterial compliance were not significantly different in the subset of children with metabolic syndrome compared to those without. ${ }^{78}$ However, individual components of the metabolic syndrome and their potential relationships to IMT were not analyzed in that study. Nevertheless, there does appear to be some relationship between glycemic control and vascular structural pathology since carotid IMT is reported higher in both children with type 1 diabetes and young adults with type 2 diabetes. In children with type 1 diabetes carotid IMT values were $12 \%$ higher than age-matched peers with similar BMI, lipids and blood pressure. ${ }^{72}$ The effect of type 2 diabetes on IMT in early life has only recently been reported. Urbina and colleages ${ }^{94}$ showed that carotid IMT was higher in children and young adults (age range 10-24 years) with type 2 diabetes compared to lean or obese peers when measured at the common carotid or carotid bulb with a trend to be higher at the internal carotid site as well. As might be expected for a group of children who developed type 2 diabetes at such a young age, the diabetic group in that study had several confounding risk factors compared to the lean or obese nondiabetic groups, including abnormalities in blood pressure, total cholesterol, triglycerides, glucose and insulin, all of which might have contributed so these differences may contribute to the variation in IMT results observed. Nevertheless, modeling analysis showed that the predicted increase in IMT from the age of 10-24 years was negligible in lean participants, but accelerated by both obesity and type 2 diabetes. Although the study was cross-sectional, these findings support the likelihood that childhood obesity and early onset diabetes accelerate the appearance of atherosclerosis in adulthood.

Further support that childhood obesity and presence of risk factors negatively affect vascular health in adulthood has been provided by prospective studies that followed children for $\geq 3$ decades. The Muscatine Study (Muscatine, IO), which began data collection on 14,000 school children in the 1970s showed that risk factors measured at the age of 8-11 years were predictive of IMT in a subset of 750 participants when those men and women reached the age of 33-42 years. ${ }^{32}$ Adult IMT was positively associated with childhood LDL-C concentration in both males and females, tryglyceride concentration and BMI in females, and HDL-C and diastolic blood pressure in males. A similar investigation over the same time period, the Bogalusa Heart Study (Bogalusa, LA), confirmed that elevated LDL-C and BMI in childhood were positive predictors of carotid IMT in adulthood. ${ }^{11}$ Further analysis of those data showed that both childhood and adult BMI explained variation in the adult IMT value. ${ }^{110}$ After controlling for several covarites the effect of childhood obesity on adult IMT was smaller than the effect of adult obesity, but childhood obesity remained a statisitically significant predictor. The unique finding was that neither obese children who were no longer obese adults, 
nor lean children who did not become obese until adulthood, had elevated IMT when measured in their 30's. ${ }^{110}$ Perhaps the key message to emerge from these studies is that long term obesity, present from childhood into adulthood, is most likely to be associated with elevated IMT. A similar longitudinal study conducted in Finland has reached many of the same conclusions, and has recently reported that childhood levels of serum apolipoproteins B and A-I, measured at the age of 8-10 years, were significantly correlated with carotid IMT when measured in young adulthood (24-39 years). ${ }^{7}$ Furthermore, the Finnish group found that the apo B/apo A-I ratio was a better predictor of adult IMT than either LDL-C or LDL/HDL ratio. Collectively, these studies indicate that obesity status tracks from childhood into adulthood, and emphasize the need to prevent obesity early in life.

\section{Prevention and clinical management of vascular dysfunction}

Management of risk factors with or without diabetes begins with lifestyle prescription and education. Incorporation of intensive diet and exercise instruction can effectively modify components of the metabolic syndrome for a year or more, ${ }^{122}$ and improve endothelial function. ${ }^{61}$ There is a tendency to prescribe dietary change with or without the assistance of a dietitian in the clinical setting, whereas exercise training is rarely prescribed, but should be strongly encouraged for the benefits outlined below. Exercise can improve insulin sensitivity, glycemic control, endothelial vascular function, and blood pressure. ${ }^{123}$ It has been recommended that all children with diabetes diagnosed at or after puberty have a fasting lipid profile performed soon after diagnosis when the blood glucose has been brought under control. ${ }^{122}$ If lipids are abnormal, annual monitoring is recommended. Initial therapy should consist of optimizing glucose control with exercise and diet, prescribing an American Heart Association step 2 diet with the main goal of lowering the saturated fat in the diet. We believe that the goal of lipid control in children and adolescents with type 2 diabetes should be to reduce LDL-C to less than $100 \mathrm{mg} / \mathrm{dL}(2.6 \mathrm{mmol} / \mathrm{L})$, a goal which can often be difficult to attain with optimal glucose control and diet alone. When lifestyle interventions fail, pharmacological treatments should be considered as outlined below.

Family history, reflecting combined effects of genetics and environmental influence, are strongly associated with vascular health and attempts at treatment. For example, families with type 2 diabetes history are more likely to have increased coronary artery calcification. ${ }^{14}$ In normoglycemic and normotensive adult offspring of type 2 diabetic parents, endothelial function was lower and arterial stiffness higher, independent of metabolic syndrome in one study ${ }^{15}$ while another study reported normal carotid IMT but decreased carotid compliance in diabetic offspring. ${ }^{16}$ Likewise, young adults with diabetic parents were shown to have lower peripheral arterial compliance (higher PWV) than age-matched controls without diabetes history. ${ }^{17}$ Thus, all treatment goals and progress should be evaluated in light of familial influence.

\section{Exercise and diet}

There is evidence that physical activity and diet exert strong effects on vascular measurements in children. A study of nearly 500 adolescents demonstrated a positive relationship between FMD score and leisure time physical activity assessed by questionnaire in 13-year-old boys, ${ }^{124}$ although this relationship did not hold for girls. The authors suggested that the lower physical activity values reported for girls may account for the difference between sexes, but there may also be some variability introduced by assessing habitual activity by questionnaire. Using a more objective approach to assess energy expenditure with the doubly labeled water technique, Abbott and colleagues ${ }^{125}$ reported that free-living physical activity was positively related to FMD in a group of 47 boys and girls aged 5-10 years, even after accounting for effects of age and body fatness. Similarly, FMD was shown to be positively related to physical activity in children (mean age $\sim 10$ years) using physical activity monitors to measure body movement. ${ }^{126}$ In that study the amount of moderate-to-vigorous activity was most closely associated with FMD values, whereas the volume of low level activity, such as activities of daily living, was unrelated to endothelial function.

Several investigations have shown that moderate intensity exercise can improve endothelial function in adults, including those with diabetes, hyperlipidemia, or cardiovascular disease. ${ }^{127}$ By comparison, cessation of physical activity in healthy adults during bed rest results in a rapid decline in the reactive hyperemic response within 3-5 days. ${ }^{128}$ The effect of exercise has been proposed to be potentially independent of changes in other risk factors. Green and colleagues ${ }^{127}$ conducted exercise training programs with combined aerobic and resistive components for eight weeks in a diverse group of middle-aged clinical patients and healthy participants. They showed that forearm FMD improved after training despite no significant changes in lipids, blood pressure, fasting glycemia, or BMI and that the change in FMD was not associated with changes in these or other risk variables. These findings 
suggest that exercise may mediate an independent effect on vascular function by repeated exposure to increased shear stress during physical activity and that concurrent improvement in endothelial function and traditional risk factors in response to training may not be causally related.

Exercise training effects on vascular measures in children typically match those in adults. Watts and colleagues ${ }^{129}$ reported that obese children aged 14 years, had FMD values that were $50 \%$ lower at baseline compared to a group of normal weight peers. In response to an eight-week aerobic and resistance exercise program, FMD was increased to the point of being similar to normal weight control values despite no significant change in body weight and only a small reduction in abdominal fat. The improvement in FMD was fully lost in a subset of the group who were retested eight weeks after training was stopped. Likewise Meyer and colleagues ${ }^{63}$ reported that obese children (mean age 14 years), had FMD values that were 55\% lower and carotid IMT values that were $28 \%$ higher than lean children of the same age. After completing a six-month aerobic exercise program consisting of swimming, walking, and sports games, FMD improved $80 \%$ and IMT declined $8 \%$, though neither change was enough to normalize differences compared with lean control values. There also were improvements in BMI, body fatness, fasting insulin, triglycerides, LDL-C and C-reactive protein, although the children remained clinically obese. More recently, FMD improved in a group of overweight children (mean age 10 years) after a 12 -week program of aerobic dance training, despite no changes in several inflammatory markers. ${ }^{130}$ Together, these findings illustrate that exercise can result in improvements in several risk factors and vascular measures associated with obesity without full correction of excess body weight, and that persistent exercise adherence may be required in order to maintain those benefits.

In contrast to exercise, dietary interventions focused on energy restriction have yielded equivocal effects on vascular function in overweight children. Kaufman and colleagues ${ }^{131}$ reported that 11-year-old children who completed a fivemonth weight loss program (mean reduction of $2.4 \mathrm{~kg}$ body weight) showed improvements in brachial FMD (15\%) and GTN-mediated dilation (20\%). These changes occurred despite no significant changes in fasting glucose, lipids, or systolic blood pressure, although diastolic pressure and C-reactive protein concentration declined. On the other hand a study by Ribeiro and colleagues ${ }^{132}$ showed that diet therapy alone, resulting in a $5 \mathrm{~kg}$ reduction in body weight over four months, did not significantly alter the forearm blood flow or blood pressure response to either mental stress or handgrip exercise in obese 10-year-old children. Blood pressure responses were higher and forearm blood flow responses were lower in the obese versus lean children at baseline. However, in that report a combination of the dietary intervention plus aerobic training on three days per week did result in improved blood pressure and blood flow responses similar to those of nonobese controls. ${ }^{132}$ Further, both diet-alone and diet-plus-exercise groups had similar reduction in body mass, fasting glucose, insulin, and total cholesterol, suggesting that exercise was primarily responsible for promoting improved vascular control.

An additional component of dietary therapy that has received attention is antioxidant supplementation. Several studies in adults showed that vitamin $\mathrm{C}$ and $\mathrm{E}$ supplementation may partially prevent the acute effect of a high fat meal to induce vascular dysfunction, measured by arterial elasticity, flow mediated dilation, or response to the vasodilator, L-arginine. ${ }^{133-135}$ Since obesity and vascular disease are frequently associated with markers of inflammation or oxidative damage, antioxidant supplementation trials have been performed, but the results have been mixed. Examples of favorable results in overweight adults include a recent study in which a daily dose of vitamins $\mathrm{C}$ and $\mathrm{E}$ plus betacarotene for eight weeks produced small improvements in levels of vascular endothelial adhesion markers. ${ }^{136}$ Another trial in middle-aged obese adults showed that fibrinolysis was improved after three months of vitamin $\mathrm{C}$ supplementation. ${ }^{137}$ The limited data available on antioxidant supplementation in children has also favored positive results. In the Endothelial Assessment of Risk from Lipids in Youth (EARLY) study a small group of participants (aged 8-20 years) with familial hyperlipidemia was given $250 \mathrm{mg}$ of vitamin $\mathrm{C}$ and $200 \mathrm{IU}$ of vitamin $\mathrm{E}$ twice daily for six weeks in a double-blind, randomized, placebo-controlled crossover trial. ${ }^{138}$ Compared to baseline, a standard diet phase, or the placebo phase, brachial FMD was significantly higher ( $\sim 60 \%)$ following the antioxidant supplement period. The improvement in FMD occurred in the absence of significant changes in blood pressure, lipids, or C-reactive protein. Using a similar study design the same investigative team also reported improvement in FMD in response to supplementation with the omega-3 fatty acid, docosahexaenoic acid (1.2 g/day), taken for six weeks by children and adolescents with hyperlipidemia. ${ }^{139}$

In contrast to those positive data, several studies have reported that experimental supplementation of vitamins $\mathrm{C}$ and/or E had no beneficial effects on, for example, arterial compliance, blood pressure or endothelial function in healthy young or older adults, adults with type 2 diabetes, or 
arterial disease patients. ${ }^{140-142}$ Likewise, most larger clinical trials of antioxidant vitamins, particularly vitamin $\mathrm{E}$, failed to demonstrate benefits on cardiovascular and mortality outcomes in adults. ${ }^{143,144}$ Of greater concern is the finding from a meta-analysis that daily supplementation of vitamin E exceeding 400 IU per day was associated with increased mortality. ${ }^{145}$ Negative results were also noted for trials of beta carotene and vitamin A. ${ }^{146}$ It should be noted that the increased risk for vitamin $\mathrm{E}$ was demonstrated in trials using vitamin E alone, which may limit its effectiveness and be responsible for the negative outcomes. Further, many trials were often small and performed on patients with chronic diseases, making the generalization to all adults and children uncertain. Vitamin $\mathrm{C}$, alone or in combination with vitamin $\mathrm{E}$ or other antioxidants, may still have some potential for beneficial application as a supplement, ${ }^{143}$ but further trials, especially in obese or diabetic children will be needed to resolve whether their use should be promoted. At present, it is recommended that children and adults receive adequate sources of antioxidant vitamins through a normal diet rich in fruits and vegetables. Following both the American Diabetes Association (ADA) and DASH diets is likely to substantially increase the antioxidant content, obviating the need for additional antioxidant supplements.

Although diet and exercise each may have beneficial effects on vascular function individually, combined exercise and nutritional interventions are employed increasingly to address the complications of obesity in children. For example, a group of 135 obese children (mean age 12 years) were enrolled in a six-month intervention program $(\mathrm{N}=75)$ consisting of behavioral, nutritional, and supervised exercise components, or a standard of care control group who continued to be observed by pediatricians and provided office-based nutritional guidance. ${ }^{147}$ The intervention group lost an average of $2.6 \mathrm{~kg}$ while the control group continued to gain weight $(5 \mathrm{~kg})$. Those in the intervention also reduced total cholesterol and fasting insulin although there was not a treatment effect on LDL-C or HDL-C or triglycerides and effects on vascular function were not described. In a smaller study lasting three months in duration, a program of combined behavioral, nutritional and aerobic exercise (walking) resulted in only a small reduction in BMI in obese adolescents but led to significant reductions in several inflammatory markers, the concentration and synthesis rate of fibrinogen, and the concentration of the fibrin split product, D-dimer. ${ }^{24,25}$ These findings suggest that thrombotic risk, which is increased in obese children, is reduced following a relatively short intervention period with modest changes in behavior.

\section{Pharmacological treatment}

Since the prevalence of obesity and type 2 diabetes in childhood and adolescents has risen rapidly over just the past two decades, there has been scant scientific evidence gathered to fully evaluate the efficacy of pharmacological treatments on vascular outcomes in such children. Treatment guidelines for glycemic, lipid, and blood pressure control in children have been proposed in recent years, and are discussed below. Guidelines for management of hypertension in children are included but are reviewed in more detail elsewhere. ${ }^{148}$

\section{Glycemic control}

The first line of pharmacologic treatment for newly diagnosed children with type 2 diabetes is metformin. Metformin is well tolerated in children ${ }^{149}$ and has a favorable effect on glucose control primarily by decreasing hepatic glucose production. Metformin treatment is also associated with less weight gain compared to other oral agents, lowers triglyceride levels, and may modify cardiovascular risk. People with obesity without diabetes, who have failed lifestyle management, increasingly are being treated with metformin, particularly if they have impaired glucose tolerance, polycystic ovarian syndrome, and/or have a family history of diabetes. ${ }^{150}$ There are only minor and transient side effects associated with metformin therapy in the majority of adolescent patients. ${ }^{150}$ Mild abdominal discomfort and diarrhea are the most frequent and usually resolve within six weeks. The risk of lactic acidosis in type 2 diabetic patients treated with metformin is approximately 0.03 per 1,000 patient years; the predisposing factors for acidosis in adults are renal and/or atherosclerotic cardiovascular disease, liver disease, or alcohol abuse. ${ }^{151-153}$ Long-term metformin use may be associated with decreased intestinal absorption of vitamin $\mathrm{B}_{12}$ and folate but the magnitude of reductions in plasma $\mathrm{B}_{12}$ and folate are not believed to be significant in adults and can be reversed on discontinuation. ${ }^{153}$ Comparable data in adolescents are needed.

\section{Lipid management}

Guidelines from the ADA, incorporating recommendations by the American Heart Association (AHA), suggest the use of pharmacologic agents (statins) when the LDL-C remains above $130 \mathrm{mg} / \mathrm{dL}(3.4 \mathrm{mmol} / \mathrm{L})$ after lifestyle intervention, when one or more cardiovascular disease risk factors (including diabetes) is present. The authors recommend the use of a statin in type 2 diabetic with the goal of attaining an LDL-C of less than $100 \mathrm{mg} / \mathrm{dL}(2.6 \mathrm{mmol} / \mathrm{L})$, since safety and efficacy have been documented in children with familial hypercholesterolemia as young as eight years old. ${ }^{154}$ Statins may have additional benefit for the diabetic patient since they 
have the effect of reducing inflammation and oxidation via their pleiotrophic effects. ${ }^{155}$

Other less effective agents can be used for hyperlipidemia, either alone or in combination with a statin. Bile acid-binding resins have a long track record of safety in children, but have not been well tolerated because of failure to dissolve as a powder, resulting in an unpleasant gritty and sandy taste. Cholesevelam, taken as a large-sized $625 \mathrm{mg}$ pill, has successfully lowered lipids, with improved palatability, although cramping and bloating can be expected. These effects can be offset by the concomitant use of psyllium-containing laxatives. Niacin has not been acceptable for use in childhood because of the frequent occurrence of flushing and elevation in liver enzymes. ${ }^{156}$ Early evidence supports safety, efficacy and low side effect profile in children with familial hypercholesterolemia for ezetimibe (Zetia), a specific cholesterol absorption inhibitor acting on the Nieman-Pick-Like L1 protein located on the intestinal brush border endothelium. ${ }^{157}$ This drug has potential for use alone and in combination with a statin. The dual synergistic effect on inhibiting intestinal cholesterol absorption and down-regulating the increased hepatic cholesterol synthesis may lower the dose requirement of concomitant statin used. However, a study on intensive lipid lowering with combined simvastatin and ezetimibe in aortic stenosis (SEAS) demonstrated limited efficacy while cancer occurred more frequently in the combination treatment group. ${ }^{158}$ Subsequently analyses from three ezetimibe trials failed to provide clear evidence that the drug affected cancer rates $^{159}$ and pre-clinical testing failed to show tumor-promoting effects. ${ }^{160}$ Nevertheless, longer follow-up for potential cancer risk has been recommended. ${ }^{159}$ In adults ezetimibe has largely been used in combination with high statin doses in efforts to attain recommended lipid goals. Since lipid goal achievement may be attained in combination at a lower statin dose than that required with a statin alone, the combination may be especially attractive in children. Ezetimibe monotherapy has been shown in a small retrospective series involving children and adolescents ${ }^{157}$ to be safe and efficacious for lowering LDL-C. Consequently it has been recommended as a suitable choice considering its good palatability compared to bile acid-binding resins, low side-effect profile and less than $20 \%$ gastrointestinal absorption.

Unfortunately, additional treatment targets including triglyceride and HDL-C values have rarely been considered in childhood, even though they are recognized components of the metabolic syndrome, and incremental benefit on cardiovascular risk may be attained by aggressive treatment of these components. Recent treatment consensus recommendations for triglycerides have been published. ${ }^{161}$ Treatment of triglyceride concentrations between 150 and $400 \mathrm{mg} / \mathrm{dL}$ consists of limiting of dietary intake of simple sugars and saturated and trans fats, and weight loss management incorporating physical activity. In obese children aged over 10 years, use of a fibrate should be considered when the triglyceride is above $700 \mathrm{mg} / \mathrm{dL}$ to offset the risk of pancreatitis. It should be noted however that combining a fibrate with a statin is contraindicated in childhood because of the increased potential for myopathy and rhabdomyolysis. It is likely that the emergence of newer technologies allowing measurements of vascular pathology (IMT, PCA, PWV, etc.) may serve as a stimulus for a reappraisal of treatment guidelines related to the use of pharmacologic agents in treatment of various forms of hyperlipidemia.

An HDL-C target for children with type 2 diabetes has not been established other than to attempt normalization by increasing physical activity. A meta-analysis of randomized controlled trials showed that aerobic exercise decreases triglycerides in obese and overweight children and adolescents with a trend for increased HDL-C. ${ }^{162}$ Nevertheless, levels of HDL-C often remain below the normal range in the face of insulin resistance with or without diabetes. Treatment of elevated cholesterol or triglyceride with a statin or a fibrate may have a moderate effect on rasing HDL-C. Low HDL-C concentration and resistance to change in response to treatment in insulin resistant patients may in part be mediated by a pleiotropic effect of specific genes on elevating triglyceride and lowering HDL-C. ${ }^{163,164}$

At the onset of type 2 diabetes it is common to find hypertriglyceridemia, low HDL-C and moderately high LDL-C accompanying insulin resistance and relative beta cell failure. Consequently high rates of dyslipidemia in type 2 diabetes approaching and exceeding $50 \%$, have been recorded, depending on the definition. ${ }^{165,166}$ Dyslipidemia is often reversible with adequate diabetes treatment, but in many cases the primary LDL-C target is not achieved and ongoing treatment with lipid-lowering medications is indicated. Prevalence rates for abnormal LDL-C greater than 160,130 , and $100 \mathrm{mg} / \mathrm{dL}$ in youth with type 2 diabetes have been reported as $9 \%, 24 \%$, and $57 \%,{ }^{167}$ much higher than those with type 1 diabetes $(3 \%, 14 \%$, and $48 \%$ for the same LDL-C cut points). However, data suggest that physicians tend to use lipid-lowering therapy sparingly, possibly because of a lack of outcome data for this age group. ${ }^{167}$ Compliance with ADA and AHA guidelines requires a more aggressive approach than is currently practiced to achieve optimal glycemic control and attain the recommended primary 
target (LDL-C $<100 \mathrm{mg} / \mathrm{dL}$ ) and secondary targets (HDL-C $>35 \mathrm{mg} / \mathrm{dL}$, triglyceride $<150 \mathrm{mg} / \mathrm{dL}$ ). ${ }^{166}$ This needs to begin with comprehensive lifestyle education with family participation and should include discussion of weight control, tobacco cessation and physical activity. Since the decision to treat with a lipid-lowering agent is based on lipid levels and associated risk factors, regular and accurate monitoring at least every three months is required for assessing the status of the conventional metabolic syndrome criteria (height and weight measurements to determine BMI, lipid profile, including triglyceride, cholesterol, HDL-C, calculated LDL-C and non-HDL-C and blood pressure.

Additional nontraditional markers of cardiovascular disease in children are available and might support a decision to treat, particularly when there is a family history of cardiovascular events. ${ }^{168}$ Such novel markers of risk are generally only recommended as part of approved ongoing investigations and should not be relied on as predictors without conclusive data in this age group. Nevertheless, popular lipid/lipoprotein measures known to predict risk in adults such as apoB, LDL particle number and non-HDL (obtained by subtracting the HDL-C from the total cholesterol) and Lp(a) may be helpful to guide treatment decisions, although normal ranges for adolescents have not been established. Non-HDL-C levels are approximately $30 \mathrm{mg} / \mathrm{dL}$ above those for LDL-C. C-reactive protein assay is available as an inflammatory marker and a predictor of cardiovascular disease in the patient without other causes of transient inflammation. Elevated C-reactive protein has been associated with obesity in adolescents, ${ }^{169}$ but is not specific to obesity and may be spuriously increased by acute and chronic inflammatory conditions. Elevated liver enzymes such as alanine aminotransferase and aspartic acid aminotransferase, have recently been observed in association with the metabolic syndrome in obese children, indicating the presence of hepatic steatosis. ${ }^{170}$ IMT tends to be increased in adolescent patients with steatosis suggesting additional cardiovascular risk. ${ }^{171}$ Therefore moderate transaminase elevation, a common finding at the onset of type 2 diabetes, warrants detection, evaluation and intensification of the treatment plan. ${ }^{172}$

The decision to treat elevated LDL-C with a statin must take into consideration its possible long-term harmful effects. Pregnancy counseling and avoidance of teratogenic effects need to be considered when prescribing for the teenage female. Cross-reactivity with other agents with common disposal pathways can result in increased levels of the statin and risk for myositis and potential rhabdomyolysis, although the risk is lower at young ages and when the patient is free of renal and hepatic disease. Consequently monitoring for increases in muscle creatinine kinase and liver enzymes is recommended at baseline and if symptoms occur. There is ample short-term trial evidence for efficacy and safety of statins in adolescence, although trials for statins and other lipid-lowering agents are ongoing. ${ }^{155,173}$

\section{Hypertension}

It has been estimated that hypertension is eight times more frequent in adolescents with type 2 diabetes than with type 1 diabetes ${ }^{165}$ and the prevalence at presentation varies between $10 \%$ to $32 \% .{ }^{174,175}$ The incidence of hypertension (systolic or diastolic blood pressure $>95$ th percentile) in the recent TODAY trial was $17 \%$, with $29 \%$ of type 2 diabetic subjects having a blood pressure greater than the 90th percentile, according to age, sex, and height. ${ }^{5}$ After controlling diabetes, the recommended approach to treatment of hypertension is to begin with lifestyle. The 4th taskforce of the High Blood Pressure Education Program recommends the dietary principals of the Dietary Approaches to Stop Hypertension (DASH) diet consisting of fruits, vegetables, low fat dairy, whole grains, reduced saturated fat, refined sugar, and low salt. ${ }^{148}$ Since there is overlap with components of the ADA recommendations for diabetes, the recommended dietary plans are compatible, with the emphasis on low salt intake if hypertension is present.

The 4th taskforce guidelines also recommend treatment to a goal of less than the 95 th percentile for primary hypertension and less than the 90th percentile for patients with diabetes or when there is evidence of target organ damage. ACE inhibitors are considered as first line pharmacological treatment and there are efficacy and safety data for the use of enalapril, fosinopril, and lisinopril in childhood. ${ }^{176}$ Prior to treatment a baseline measurement of renin activity is recommended as a guide to whether there is salt-sensitivity or a renal-vascular component and can serve to aid in selection of treatment. If the renin is low, a diuretic is indicated, as in adults. ${ }^{177}$ The treatment sequence should begin with the recommended initial dose of the desired medication and an increase in the dose until the blood pressure target or maximum dose is reached. If blood pressure control is not achieved, a second medication with a complementary mechanism of action should be added. If blood pressure control is still not achieved a third antihypertensive drug of a different class may be added, but at this point it is advisable to consult a physician specializing in treatment of children and adolescents with hypertension. Cases with an elevated plasma renin activity need urgent consultation. 
Table I Summary of changes in vascular measures during child and adult development, and the effects of obesity and type 2 diabetes

\begin{tabular}{|c|c|c|c|c|}
\hline & $\begin{array}{l}\text { Development pattern in } \\
\text { childhood }\end{array}$ & $\begin{array}{l}\text { Change with age in } \\
\text { adulthood }\end{array}$ & Effect of obesity & Effect of type 2 diabetes \\
\hline Endothelial function & $\begin{array}{l}\text { No change or reduced; limited } \\
\text { age and developmental stage- } \\
\text { related norms }\end{array}$ & $\begin{array}{l}\text { Reduced, preserved } \\
\text { in exercisers }\end{array}$ & $\begin{array}{l}\text { Reduced in children and } \\
\text { adults }\end{array}$ & $\begin{array}{l}\text { Reduced in adults, no data in } \\
\text { children }\end{array}$ \\
\hline Arterial compliance & $\begin{array}{l}\text { Increased; limited age and } \\
\text { developmental stage-related } \\
\text { norms }\end{array}$ & $\begin{array}{l}\text { Reduced, preserved } \\
\text { in exercisers }\end{array}$ & $\begin{array}{l}\text { Reduced in most studies of } \\
\text { children and adults; recent } \\
\text { data in children conflicting }\end{array}$ & $\begin{array}{l}\text { Reduced in adults, no change } \\
\text { in children }\end{array}$ \\
\hline Intima-media thickness & $\begin{array}{l}\text { No change or increased } \\
\text { slightly }\end{array}$ & Increased & $\begin{array}{l}\text { Increased in most studies } \\
\text { (both children and adults), no } \\
\text { change in prepubertal children }\end{array}$ & $\begin{array}{l}\text { Increased in adults and } \\
\text { adolescents }\end{array}$ \\
\hline
\end{tabular}

\section{Future directions and conclusions}

Extensive evidence suggests that the foundations for vascular disease in adults are laid in childhood and accelerated by the co-existence of disease, including but not limited to diabetes, hypertension, obesity, and hyperlipidemia. As summarized in Table 1, current understanding of the effects of obesity and type 2 diabetes on vascular health in youth is incomplete. However, the recent development of noninvasive methods for assessing vascular health has made it possible to make precise and reproducible measures of vascular function and anatomic pathology early in the course of development of vascular disease, and is expected to result in the proliferation of data related to its origins. Current evidence suggests that many of the risk factors for vascular disease can be reduced by early intervention, including both lifestyle (dietary, exercise, and simple changes in physical activity) and pharmacologic (glycemic, blood pressure, and lipid control) interventions. The inevitable progression of vascular disease with aging suggests that the management of risk factors for vascular disease should begin with prevention, through early lifestyle interventions, well before the development of obesity and diabetes. Unfortunately, lifestyle interventions can be costly, are poorly reimbursed, and often ineffective due to poor compliance, resulting in the need for pharmacologic intervention. When attempts at lifestyle modification fail, the use of pharmacologic interventions (to effect glucose, blood pressure, and lipid control), even in childhood, are recommended, with careful monitoring and a willingness to alter the prescribed therapy as needed in order to achieve the target values outlined by expert panels.

\section{Acknowledgments}

KRS is supported by research funding from the Oklahoma Center for the Advancement of Science and Technology (HR07-156S) and Grant Number P20RR024215 from the National Center for Research Resources. AWG is supported by grants from the National Institute on Aging (R01-AG-24296), National Center on Minority Health and Health Disparities (P20-MD-000528), National Center for Research Resources (M01-RR-14467 and P20-RR-024215), and Oklahoma Center for the Advancement of Science and Technology (HR09-035). KCC is supported by research funding from the National Institutes of Health (U01-DK061230-09). The content is solely the responsibility of the authors and does not necessarily represent the official views of the National Center for Research Resources or the National Institutes of Health. The authors report no conflicts of interest in this work.

\section{References}

1. Copeland KC, Chalmers LJ, Brown RD. Type 2 diabetes in children: oxymoron or medical metamorphosis? Pediatr Ann. 2005;34: 686-697.

2. Sinha R, Fisch G, Teague B, et al. Prevalence of impaired glucose tolerance among children and adolescents with marked obesity. $N$ Engl J Med. 2002;346:802-810.

3. Liu LL, Lawrence JM, Davis C, et al. Prevalence of overweight and obesity in youth with diabetes in USA: the SEARCH for Diabetes in Youth Study. Pediatr Diab. 2009 May 15. [Epub ahead of print].

4. SEARCH for Diabetes in Youth Study Group, Liese AD, D'Agostino RB, et al. The burden of diabetes mellitus among US youth: prevalence estimates from the SEARCH for Diabetes in Youth Study. Pediatrics. 2006;118:1510-1518.

5. White NH, Pyle L, Tamborlane WV, et al. Clinical characteristics and co-morbidities in a large cohort of youth with type 2 diabetes mellitus (T2DM) screened for the Treatment Options for Type 2 Diabetes in Adolescents and Youth (TODAY) Study. Diabetes. 2009; 58(Suppl 1):A70.

6. The TODAY Study Group, Zeitler P, Epstein L, et al; Treatment options for type 2 diabetes in adolescents and youth: a study of the comparative efficacy of metformin alone or in combination with rosiglitazone or lifestyle intervention in adolescents with type 2 diabetes. Pediatr Diab. 2007;8:74-87.

7. Juonala M, Viikari JS, Kähönen M, et al. Childhood levels of serum apolipoproteins B and A-I predict carotid intima-media thickness and brachial endothelial function in adulthood: the cardiovascular risk in young Finns study. J Am Coll Cardiol. 2008;52:293-299.

8. Koskinen J, Kähönen M, Viikari JS, et al. Conventional cardiovascular risk factors and metabolic syndrome in predicting carotid intima-media thickness progression in young adults. The Cardiovascular Risk in Young Finns Study. Circulation. 2009;120:229-236. 
9. Halcox JPJ, Donald AE, Ellins E, et al. Endothelial function predicts progression of carotid intima-media thickness. Circulation. 2009;119:1005-1012.

10. Duprez DA, Somasundaram PE, Sigurdsson G, et al. Relationship between C-reactive protein and arterial stiffness in an asymptomatic population. J Hum Hypertens. 2005;19:515-519.

11. Freedman DS, Dietz WH, Tang R, et al; The relation of obesity throughout life to carotid intima-media thickness in adulthood: the Bogalusa Heart Study. Int J Obes Relat Metab Disord. 2004;28:156-166.

12. Ikonomidis I, Stamatelopoulos K, Lekakis J, Vamvakou GD, Kremastinos DT. Inflammatory and non-invasive vascular markers: the multimarker approach for risk stratification in coronary artery disease. Atherosclerosis. 2008;199:3-11.

13. Aggoun Y, Farpour-Lambert NJ, Marchand LM, et al. Impaired endothelial and smooth muscle functions and arterial stiffness appear before puberty in obese children and are associated with elevated ambulatory blood pressure. Eur Heart J. 2008;29:792-799.

14. Wagenknecht LE, Bowden DW, Carr JJ, et al. Familial aggregation of coronary artery calcium in families with type 2 diabetes. Diabetes. 2001;50:861-866.

15. Scuteri A, Tesauro M, Rizza S, et al. Endothelial function and arterial stiffness in normotensive normoglycemic first-degree relatives of diabetic patients are independent of the metabolic syndrome. Nutr Metab Cardiovasc Dis. 2008;18:349-356.

16. Giannattasio C, Failla M, Capra A, et al. Increased arterial stiffness in normoglycemic normotensive offspring of type 2 diabetic parents. Hypertension. 2008;51:182-187.

17. McEleavy OD, McCallum RW, Petrie JR, et al. Higher carotid-radial pulse wave velocity in healthy offspring of patients with Type 2 diabetes. Diabet Med. 2004;21:262-266.

18. McGill Jr HC, McMahan CA, Herderick EE, et al. Effects of coronary heart disease risk factors on atherosclerosis of selected regions of the aorta and right coronary artery. PDAY Research Group. Pathobiological Determinants of Atherosclerosis in Youth. Arterioscler Thromb Vasc Biol. 2000;20:836-845.

19. Peña AS, Wiltshire E, MacKenzie K, et al. Vascular endothelial and smooth muscle function relates to body mass index and glucose in obese and nonobese children. J Clin Endocrinol Metab. 2006;91: 4467-4471.

20. Caballero AE, Bousquet-Santos K, Robles-Osorio L, et al. Overweight Latino children and adolescents have marked endothelial dysfunction and subclinical vascular inflammation in association with excess body fat and insulin resistance. Diabetes Care. 2008;31:576-582.

21. Kapiotis S, Holzer G, Schaller G, et al. A proinflammatory state Is detectable in obese children and is accompanied by functional and morphological vascular changes. Arterioscler Thromb Vasc Biol. 2006;26:2541-2546.

22. Meyer AA, Kundt G, Steiner M, Schuff-Werner P, Kienast W. Impaired flow-mediated vasodilation, carotid artery intima-media thickening, and elevated endothelial plasma markers in obese children: the impact of cardiovascular risk factors. Pediatrics. 2006;117:1560-1567.

23. Reinehr T, Kiess W, de Sousa G, Stoffel-Wagner B, Wunsch R. Intima media thickness in childhood obesity: Relations to inflammatory marker, glucose metabolism, and blood pressure. Metabolism. 2006;55: 113-118.

24. Balagopal P, George D, Patton N, et al. Lifestyle-only intervention attenuates the inflammatory state associated with obesity - a randomized controlled study in adolescents. J Pediatr. 2005;146:342-348.

25. Balagopal P, George D, Sweeten S, et al. Response of fractional synthesis rate (FSR) of fibrinogen, concentration of D-dimer and fibrinolytic balance to physical activity-based intervention in obese children. J Thromb Haemost. 2008;6:1296-1303.

26. Cali AMG, Zern TL, Taksali SE, et al. Intrahepatic fat accumulation and alterations in lipoprotein composition in obese adolescents. Diabetes Care. 2007;30:3093-3098.

27. Mangge H, Almer G, Haj-Yahya S, et al. Preatherosclerosis and adiponectin subfractions in obese adolescents. Obesity. 2008;16:2578-2584.
28. Winer JC, Zern TL, Taksali SE, et al. Adiponectin in childhood and adolescent obesity and its association with inflammatory markers and components of the metabolic syndrome. J Clin Endocrinol Metab. 2006;91:4415-4423.

29. Weiss R, Shaw M, Savoye M, Caprio S. Obesity dynamics and cardiovascular risk factor stability in obese adolescents. Pediatr Diabetes. 2009 Mar 11. [Epub ahead of print].

30. Eisenmann JC, Welk GJ, Wickel EE, Blair SN. Stability of variables associated with the metabolic syndrome from adolescence to adulthood: the Aerobics Center Longitudinal Study. Am J Hum Biol. 2004;16:690-696.

31. Frontini MG, Srinivasan SR, Xu J, et al; Usefulness of childhood nonhigh density lipoprotein cholesterol levels versus other lipoprotein measures in predicting adult subclinical atherosclerosis: the Bogalusa Heart Study. Pediatrics. 2008;121:924-929.

32. Davis PH, Dawson JD, Riley WA, Lauer RM. Carotid intimal-medial thickness is related to cardiovascular risk factors measured from childhood through middle age: the Muscatine Study. Circulation. 2001;104:2815-2819.

33. Tschakovsky ME, Pyke KE. Counterpoint: Flow-mediated dilation does not reflect nitric oxide-mediated endothelial function. J Appl Physiol. 2005;99:1235-1237.

34. Thomas GD. Flow-mediated dilation and biological variability. J Appl Physiol. 2005;99:1626.

35. Tanaka H. FMD vs pharmacological approaches for endothelial function. J Appl Physiol. 2005;99:1627.

36. Green D. Point: Flow-mediated dilation does reflect nitric oxidemediated endothelial function. $J$ Appl Physiol. 2005;99:1233-1234.

37. Celermajer DS. Brachial artery FMD with 5-minute distal cuff occlusion - a useful pathophysiological test after all! J Appl Physiol. 2005;99:1619.

38. Celermajer DS. Testing endothelial function using ultrasound. J Cardiovasc Pharmacol. 1998;32(Suppl 3):S29-S32.

39. Celermajer DS, Sorensen KE, Gooch VM, et al. Non-invasive detection of endothelial dysfunction in children and adults at risk of atherosclerosis. Lancet. 1992;340:1111-1115.

40. Corretti MC, Anderson TJ, Benjamin EJ, et al. Guidelines for the ultrasound assessment of endothelial-dependent flow-mediated vasodilation of the brachial artery: a report of the International Brachial Artery Reactivity Task Force. J Am Coll Cardiol. 2002;39: 257-265.

41. Skilton MR, Celermajer DS. Endothelial dysfunction and arterial abnormalities in childhood obesity. Int $J$ Obes. 2006;30: 1041-1049.

42. Black MA, Cable NT, Thijssen DHJ, Green DJ. Importance of measuring the time course of flow-mediated dilatation in humans. Hypertension. 2008;51:203-210.

43. Celermajer DS. Endothelial dysfunction: does it matter? Is it reversible? J Am Coll Cardiol. 1997;30:325-333.

44. Fernhall B, Agiovlasitis S. Arterial function in youth: window into cardiovascular risk. J Appl Physiol. 2008;105:325-333.

45. Dengel DR, Kelly AS, Steinberger J, Sinaikos AR. Effect of oral glucose loading on endothelial function in normal-weight and overweight children. Clin Sci. 2007;112:493-498.

46. Järvisalo MJ, Lehtimäki T, Raitakari OT. Determinants of arterial nitrate-mediated dilatation in children: role of oxidized low-density lipoprotein, endothelial function, and carotid intima-media thickness. Circulation. 2004;109:2885-2889.

47. Sejda T, Pit'ha J, Svandova E, Poledne R. Limitations of non-invasive endothelial function assessment by brachial artery flow-mediated dilatation. Clin Physiol Funct Imaging. 2005;25:58-61.

48. Qureshi E, Diamond GA, Chouraqui P, et al. Usefulness of finger blood flow during exercise as a marker of functionally signicficant coronary heart disease. Am J Cardiol. 2002;90:756-759.

49. Haller MJ, Stein J, Shuster J, et al. Peripheral artery tonometry demonstrates altered endothelial function in children with type 1 diabetes. Pediatr Diab. 2007;8:193-198. 
50. Haller MJ, Silverstein JH, Shuster JJ. Correlation between radial artery tonometry- and fingertip tonometry-derived augmentation index in children with type 1 diabetes. Diabetes Vasc Dis Research. 2007;4:66

51. Gul K, Ahmadi N, Wang Z, et al. Digital thermal monitoring of vascular function: a novel tool to improve cardiovascular risk assessment. Vasc Med. 2009;14:143-148.

52. Dhindsa M, Sommerlad SM, DeVan AE, et al. Interrelationships among noninvasive measures of postischemic macro- and microvascular reactivity. J Appl Physiol. 2008;105:427-432.

53. Ahmadi N, Hajsadeghi F, Gul K, et al. Relations between digital thermal monitoring of vascular function, the Framingham risk score, and coronary artery calcium score. J Cardiovasc Comput Tomogr. 2008;2:382-388.

54. Hamburg NM, Keyes MJ, Larson MG, et al; Cross-sectional relations of digital vascular function to cardiovascular risk factors in the Framingham Heart Study. Circulation. 2008;117:2467-2474.

55. Selamet Tierney ES, Newburger JW, Gauvreau K, et al. Endothelial pulse amplitude testing: feasibility and reproducibility in adolescents. Pediatr Res. 2009;154:901-905.

56. Nishiyama SK, Wray DW, Richardson RS. Aging affects vascular structure and function in a limb-specific manner. J Appl Physiol. 2008;105:1661-1670.

57. Thijssen DHJ, Bullens LM, van Bemmel MM, et al. Does arterial shear explain the magnitude of flow-mediated dilation? A comparison between young and older humans. Am J Physiol Heart Circ Physiol. 2009;296: H57-H64.

58. Walker AE, Eskurza I, Pierce GL, Gates PE, Seals DR. Modulation of vascular endothelial function by low-density lipoprotein cholesterol with aging: influence of habitual exercise. Am J Hypertens. 2009;22: 250-256.

59. Parker BA, Ridout SJ, Proctor DN. Age and flow-mediated dilation: a comparison of dilatory responsiveness in the brachial and popliteal arteries. Am J Physiol Heart Circ Physiol. 2006;291:H3043-H3049.

60. Jarvisalo MJ, Ronnemaa T, Volanen I, et al. Brachial artery dilatation responses in healthy children and adolescents. Am J Physiol Heart Circ Physiol. 2002;282:H87-H92.

61. Woo KS, Chook P, Yu CW, et al. Effects of diet and exercise on obesity related vascular dysfunction in children. Circulation. 2004;109: 1981-1986.

62. Tounian P, Aggoun Y, Dubern B, et al. Presence of increased stiffness of the common carotid artery and endothelial dysfunction in severely obese children: a prospective study. Lancet. 2001;358 1400-1404.

63. Meyer AA, Kundt G, Lenschow U, Schuff-Werner P, Kienast W. Improvement of early vascular changes and cardiovascular risk factors in obese children after a six-month exercise program. J Am Coll Cardiol. 2006;48:1865-1870.

64. Singhal A. Endothelial dysfunction: role in obesity-related disorders and the early origins of CVD. Proc Nutr Soc. 2005;64:15-22.

65. Aggoun Y, Szezepanski I, Bonnet D. Noninvasive assessment of arterial stiffness and risk of atherosclerotic events in children. Pediatr Res. 2005;58:173-178.

66. Karpoff L, Vinet A, Schuster I, et al. Abnormal vascular reactivity at rest and exercise in obese boys. Eur J Clin Invest. 2009;39:94-102.

67. Gokce N, Keaney JF Jr, Hunter LM, et al. Predictive value of noninvasivelydetermined endothelial dysfunction for long-term cardiovascular events inpatients with peripheral vascular disease. J Am Coll Cardiol. 2003;41:1769-1775.

68. Yeboah J, Sutton-Tyrrell K, McBurnie MA, et al. Association between brachial artery reactivity and cardiovascular disease status in an elderly cohort: The cardiovascular health study. Atherosclerosis. 2008;197: 768-776.

69. Shechter M, Issachar A, Marai I, et al. Long-term association of brachial artery flow-mediated vasodilation and cardiovascular events in middle-aged subjects with no apparent heart disease. Int J Cardiol. 2009; 134:52-58.
70. Perticone F, Ceravolo R, Pujia A, et al. Prognostic significance of endothelial dysfunction in hypertensive patients. Circulation. 2001;104:191-196.

71. Odermarsky M, Nilsson A, Lernmark A, Sjoblad S, Liuba P. Atherogenic vascular and lipid phenotypes in young patients with type 1 diabetes are associated with diabetes high-risk HLA genotype. Am J Physiol Heart Circ Physiol. 2007;293:H3175-H3179.

72. Jarvisalo MJ, Raitakari M, Toikka JO, et al. Endothelial dysfunction and increased arterial intima-media thickness in children with type 1 diabetes. Circulation. 2004;109:1750-1755.

73. Caballero AE, Arora S, Saouaf R, et al. Microvascular and macrovascular reactivity is reduced in subjects at risk for type 2 diabetes. Diabetes. 1999;48:1856-1862.

74. Suys B, de Beeck LO, Rooman R, et al. Impact of oxidative stress on the endothelial dysfunction of children and adolescents with type 1 diabetes mellitus: protection by superoxide dismutase? Pediatr Res. 2007;62:456-461.

75. Ceriello A, Esposito K, Piconi L, et al. Oscillating glucose is more deleterious to endothelial function and oxidative stress than mean glucose in normal and type 2 diabetic patients. Diabetes. 2008;57: 1349-1354.

76. The Diabetes Control and Complications Trial Research Group. The relationship of glycemic exposure $\left(\mathrm{HbA}_{1 \mathrm{c}}\right)$ to the risk of development and progression of retinopathy in the Diabetes Control and Complications Trial. Diabetes. 1995;44:968-983.

77. Juonala M, Viikari JSA, Rönnemaa T, et al. Elevated blood pressure in adolescent boys predicts endothelial dysfunction: the cardiovascular risk in young Finns study. Hypertension. 2006;48:424-430.

78. Mimoun E, Aggoun Y, Pousset M, et al. Association of arterial stiffness and endothelial dysfunction with metabolic syndrome in obese children. J Pediatr. 2008;153:65-70.e61.

79. Arnett DK, Evans GW, Riley W. Arterial stiffness: a new cardiovascular risk factor? Am J Epidemiol. 1994;140:669-682.

80. Prisant LM, Pasi M, Jupin D, Prisant ME. Assessment of repeatability and correlates of arterial compliance. Blood Press Monit. 2002;7: 231-235.

81. Finkelstein SM, Cohn JN. First- and third-order models for determining arterial compliance. J Hypertens. 1992;10(Suppl):S11-S14.

82. Cohn JN. Vascular wall function as a risk marker for cardiovascular disease. J Hypertens. 1999;17(Suppl):S41-S44.

83. Cohn JN, Finkelstein S, McVeigh G, et al. Noninvasive pulse wave analysis for the early detection of vascular disease. Hypertension. 1995;26:503-508.

84. O'Rourke MF, Hashimoto J. Arterial stiffness: a modifiable cardiovascular risk factor? J Cardiopulm Rehabil Prev. 2008;28: $225-237$.

85. Willum-Hansen T, Staessen JA, Torp-Pedersen C, et al. Prognostic value of aortic pulse wave velocity as index of arterial stiffness in the general population. Circulation. 2006;113:664-670.

86. Roman MJ, Devereux RB, Kizer JR, et al; Central pressure more strongly relates to vascular disease and outcome than does brachial pressure: the Strong Heart Study. Hypertension. 2007;50:197-203.

87. Bella JN, Roman MJ, Pini R, et al. Assessment of arterial compliance by carotid midwall strain-stress relation in normotensive adults. Hypertension. 1999;33:787-792.

88. McVeigh GE, Bratteli CW, Morgan DJ, et al. Age-related abnormalities in arterial compliance identified by pressure pulse contour analysis: aging and arterial compliance. Hypertension. 1999;33:1392-1398.

89. Vaitkevicius PV, Fleg JL, Engel JH, et al. Effects of age and aerobic capacity on arterial stiffness in healthy adults. Circulation. 1993; $88: 1456-1462$.

90. Collins RT, Somes GW, Alpert BS. Arterial stiffness is increased in American adolescents compared to Japanese counterparts. Pediatr Cardiol. 2009;30(6):794-799.

91. Gardner AW, Parker DE. Association between arterial compliance and age in participants 9 to 77 years old. Angiology. 2009 Jul 27. [Epub ahead of print]. 
92. Tanaka H, Dinenno FA, Monahan KD, et al. Aging, habitual exercise, and dynamic arterial compliance. Circulation. 2000: $1270-1275$.

93. Tanaka H, Desouza CA, Seals DR. Absence of age-related increase in central arterial stiffness in physically active women. Arterioscler Thromb Vasc Biol. 1998;18:127-132.

94. Urbina EM, Kimball TR, McCoy CE, et al. Youth With obesity and obesity-related type 2 diabetes mellitus demonstrate abnormalities in carotid structure and function. Circulation. 2009;119: 2913-2919.

95. Sakuragi S, Abhayaratna K, Gravenmaker KJ, et al. Influence of adiposity and physical activity on arterial stiffness in healthy children: the lifestyle of our kids study. Hypertension. 2009;53:611-616.

96. Dangardt F, Osika W, Volkmann R, Gan LM, Friberg P. Obese children show increased intimal wall thickness and decreased pulse wave velocity. Clin Physiol Funct Imaging. 2008;28:287-293.

97. Fjeldstad AS, Fjeldstad C, Acree LS, et al. The relationship between arterial elasticity and metabolic syndrome features. Angiology. 2007;58:5-10.

98. Fjeldstad AS, Montgomery PS, Gardner AW. Age-related differences in arterial compliance are independent of body mass index. Angiology. 2008;59:454-458.

99. Nakanishi N, Suzuki K, Tatara K. Clustered features of the metabolic syndrome and the risk for increased aortic pulse wave velocity in middle-aged Japanese men. Angiology. 2003;54:551-559.

100. McVeigh G, Brennan G, Hayes R, et al. Vascular abnormalities in non-insulin-dependent diabetes mellitus identified by arterial waveform analysis. Am J Med. 1993;95:424-430.

101. Cardoso CR, Ferreira MT, Leite NC, et al. Microvascular degenerative complications are associated with increased aortic stiffness in type 2 diabetic patients. Atherosclerosis. 2009;205:472-476.

102. Prisant LM, Resnick LM, Hollenberg SM. Arterial elasticity among normotensive subjects and treated and untreated hypertensive subjects. Blood Press Monit. 2001;6:233-237.

103. Cohn JN, Finkelstein SM. Abnormalities of vascular compliance in hypertension, aging and heart failure. J Hypertens. 1992;10(Suppl): S61-S64.

104. Arnett DK, Glasser SP, McVeigh G, et al. Blood pressure and arterial compliance in young adults: the Minnesota Children's Blood Pressure Study. Am J Hypertens. 2001;14:200-205.

105. Riley WA, Freedman DS, Higgs NA, et al; Decreased arterial elasticity associated with cardiovascular disease risk factors in the young. Bogalusa Heart Study. Arteriosclerosis. 1986;6:378-386.

106. Litwin M, Trelewicz J, Wawer Z, et al. Intima-media thickness and arterial elasticity in hypertensive children: controlled study. Pediatr Nephrol. 2004;19:767-774.

107. O'Leary DH, Polak JF, Kronmal RA, et al. Carotid-artery intima and media thickness as a risk factor for myocardial infarction and stroke in older adults. $N$ Engl J Med. 1999;340:14-22.

108. Jourdan C, Wühl E, Litwin M, et al. Normative values for intima-media thickness and distensibility of large arteries in healthy adolescents. J Hypertens. 2005;23:1707-1715.

109. Sass C, Herbeth B, Chapet $\mathrm{O}$, et al. Intima-media thickness and diameter of carotid and femoral arteries in children, adolescents and adults from the Stanislas cohort: effect of age, sex, anthropometry and blood pressure. J Hypertens. 1998;16:1593-1602.

110. Freedman DS, Patel DA, Srinivasan S, et al; The contribution of childhood obesity to adult carotid intima-media thickness: the Bogalusa Heart Study. Int J Obes. 2008;32:749-756.

111. Schmidt-Trucksäss A, Cheng DC, Sandrock M, et al. Computerized analysing system using the active contour in ultrasound measurement of carotid artery intima-media thickness. Clin Physiol. 2001;21: 561-569.

112. Cheng D, Schmidt-Trucksäss A, Cheng K, Burkhardt H. Using snakes to detect the intimal and adventitial layers of the common carotid artery wall in sonography images. Comput Methods Programs Biomed. 2002;67:27-37.
113. Hansen F, Mangell P, Sonesson B, Länne T. Diameter and compliance in the human common carotid artery - variations with age and sex. Ultrasound Med Biol. 1995;21:1-9.

114. Lenard Z, Studinger P, Mersich B, Kocsis L, Kollai M. Maturation of cardiovagal autonomic function from childhood to young adult age. Circulation. 2004;110:2307-2312.

115. van Meurs-van Woezik H, Klein HW, Markus-Silvis L, Krediet P. Comparison of the growth of the tunica media of the ascending aorta, aortic isthmus and descending aorta in infants and children. J Anat. 1983;136:273-281.

116. Chambless LE, Heiss G, Folsom AR, et al; Association of coronary heart disease incidence with carotid arterial wall thickness and major risk factors: the Atherosclerosis Risk in Communities (ARIC) Study. Am J Epidemiol. 1997;146:483-494.

117. Lorenz MW, Markus HS, Bots ML, Rosvall M, Sitzer M. Prediction of clinical cardiovascular events with carotid intima-media thickness: a systematic review and meta-analysis. Circulation. 2007;115: 459-467.

118. Sorof JM, Alexandrov AV, Cardwell G, Portman RJ. Carotid artery intimal-medial thickness and left ventricular hypertrophy in children with elevated blood pressure. Pediatrics. 2003;111:61-66.

119. Lande MB, Carson NL, Roy J, Meagher CC. Effects of childhood primary hypertension on carotid intima-media thickness: a matched controlled study. Hypertension. 2006;48:40-44.

120. Tzou WS, Douglas PS, Srinivasan SR, et al; Increased subclinical atherosclerosis in young adults with metabolic syndrome. The Bogalusa Heart Study. J Am Coll Cardiol. 2005;46:457-463.

121. Toledo-Corral CM, Ventura EE, Hodis HN, et al; Persistence of the metabolic syndrome and its influence on carotid artery intima media thickness in overweight Latino children. Atherosclerosis. 2009;206: 594-598.

122. American Diabetes Association. Standards of medical care in diabetes, 2009. Diabetes Care. 2009;32:S13-S61.

123. Stewart KJ. Role of exercise training on cardiovascular disease in persons who have type 2 diabetes and hypertension. Cardiol Clin. 2004;22:569-586

124. Pahkala K, Heinonen OJ, Lagstrom H, et al. Vascular endothelial function and leisure-time physical activity in adolescents. Circulation. 2008;118:2353-2359.

125. Abbott RA, Harkness MA, Davies PS. Correlation of habitual physical activity levels with flow-mediated dilation of the brachial artery in 5-10 year old children. Atherosclerosis. 2002;160:233-239.

126. Hopkins ND, Stratton G, Tinkena TM, et al. Relationships between measures of fitness, physical activity, body composition and vascular function in children. Atherosclerosis. 2009;204:244-249.

127. Green DJ, Walsh JH, Maiorana A, et al. Exercise-induced improvement in endothelial dysfunction is not mediated by changes in CV risk factors: pooled analysis of diverse patient populations. Am J Physiol Heart Circ Physiol. 2003;285:H2679-H2687.

128. Hamburg NM, McMackin CJ, Huang AL, et al. Physical inactivity rapidly induces insulin resistance and microvascular dysfunction in healthy volunteers. Arterioscler Thromb Vasc Biol. 2007;27:2650-2656.

129. Watts K, Beye P, Siafarikas A, et al. Exercise training normalizes vascular dysfunction and improves central adiposity in obese adolescents. J Am Coll Cardiol. 2004;43:1823-1827.

130. Murphy EC, Carson L, Neal W, et al. Effects of an exercise intervention using Dance Dance Revolution on endothelial function and other risk factors in overweight children. Int J Pediatr Obes. 2009;3:1-10.

131. Kaufman CL, Kaiser DR, Kelly AS, et al. Diet revision in overweight children: effect on autonomic and vascular function. Clin Autonom Res. 2008;18:105-108.

132. Ribeiro MM, Silva AG, Santos NS, et al. Diet and exercise training restore blood pressure and vasodilatory responses during physiological maneuvers in obese children. Circulation. 2005;111:1915-1923.

133. Blendea MC, Bard M, Sowers JR, Winer N. High-fat meal impairs vascular compliance in a subgroup of young healthy subjects. Metabolism. 2005;54:1337-1344. 
134. Esposito K, Nappo F, Giugliano F, et al. Effect of dietary antioxidants on postprandial endothelial dysfunction induced by a high-fat meal in healthy subjects. Am J Clin Nutr. 2003;77:139-143.

135. Plotnick GD, Corretti MC, Vogel RA. Effect of antioxidant vitamins on the transient impairment of endothelium-dependent brachial artery vasoreactivity following a single high-fat meal. JAMA. 1997;278: $1682-1686$

136. Vincent HK, Bourguignon CM, Weltman AL, et al. Effects of antioxidant supplementation on insulin sensitivity, endothelial adhesion molecules, and oxidative stress in normal-weight and overweight young adults. Metabolism. 2009;58:254-262.

137. Van Guilder GP, Hoetzer GL, Greiner JJ, Stauffer BL, DeSouza CA Acute and chronic effects of vitamin $\mathrm{C}$ on endothelial fibrinolytic function in overweight and obese adult humans. J Physiol. 2008;586 $3525-3535$

138. Engler MM, Engler MB, Malloy MJ, et al. Antioxidant vitamins C and $\mathrm{E}$ improve endothelial function in children with hyperlipidemia: Endothelial Assessment of Risk from Lipids in Youth (EARLY) trial Circulation. 2003;108:1059-1063.

139. Engler MM, Engler MB, Malloy M, et al. Docosahexaenoic acid restores endothelial function in children with hyperlipidemia: results from the EARLY study. Int J Clin Pharmacol Ther. 2004;42: 672-679.

140. Eskurza I, Monahan KD, Robinson JA, Seals DR. Ascorbic acid does not affect large elastic artery compliance or central blood pressure in young and older men. Am J Physiol Heart Circ Physiol. 2004;286: H1528-H1534.

141. Ward NC, Wu JH, Clarke MW, et al. The effect of vitamin E on blood pressure in individuals with type 2 diabetes: a randomized, doubleblind, placebo-controlled trial. J Hypertens. 2007;25:227-234.

142. Kinlay S, Behrendt D, Fang JC, et al. Long-term effect of combined vitamins $\mathrm{E}$ and $\mathrm{C}$ on coronary and peripheral endothelial function. J Am Coll Cardiol. 2004;18:629-634.

143. Thomson MJ, Puntmann V, Kaski JC. Atherosclerosis and oxidant stress: the end of the road for antioxidant vitamin treatment? Cardiovasc Drugs Ther. 2007;21:195-210.

144. Vivekananthan DP, Penn M, Sapp S, Hsu A, Topol EJ. Use of antioxidant vitamins for the prevention of cardiovascular disease: metaanalysis of randomised trials. Lancet. 2003;361:2017-2023.

145. Miller ER, Pastor-Barriuso R, Dalal D, et al. Meta-analysis: highdosage vitamin E supplementation may increase all-cause mortality. Ann Intern Med. 2005;142:37-46.

146. Bjelakovic G, Nikolova D, Gluud LL, Simonetti RG, Gluud C. Mortality in randomized trials of antioxidant supplements for primary and secondary prevention: systematic review and meta-analysis. JAMA. 2007;297:842-857.

147. Savoye M, Shaw M, Dziura J, et al. Effects of a weight management program on body composition and metabolic parameters in overweight children: a randomized controlled trial. JAMA. 2007;297: 2697-2704.

148. National High Blood Pressure Education Program Working Group on High Blood Pressure in Children and Adolescents. The fourth report on the diagnosis, evaluation, and treatment of high blood pressure in children and adolescents. Pediatrics. 2004;114:555-576.

149. Burgert TS, Duran EJ, Goldberg-Gell R, et al. Short-term metabolic and cardiovascular effects of metformin in markedly obese adolescents with normal glucose tolerance. Pediatr Diabetes. 2008;9:567-576.

150. Freemark M, Bursey D. The effects of metformin on body mass index and glucose tolerance in obese adolescents with fasting hyperinsulinemia and a family history of type 2 diabetes. Pediatrics. 2001;107:E55.

151. Gan SC, Barr J, Arieff AI, Pearl RG. Biguanide-associated lactic acidosis. Case report and review of the literature. Arch Intern Med. 1992;152:2333-2336.

152. Aguilar C, Reza A, Garcia JE, Rull JA. Biguanide related lactic acidosis: incidence and risk factors. Arch Med Res. 1992;23:19-24.

153. Bailey CJ, Turner RC. Metformin. N Engl J Med. 1996;334: 574-579.
154. Wiegman A, Hutten BA, de Groot E, et al. Efficacy and safety of statin therapy in children with familial hypercholesterolemia: a randomized controlled trial. JAMAi. 2004;292:331-337.

155. Belay B, Belamarich PF, Tom-Revzon C. The use of statins in pediatrics: knowledge base, limitations, and future directions. Pediatrics 2007;119:370-380

156. Colletti RB, Neufeld EJ, Roff NK, McAuliffe TL, Baker AL, Newburger JW. Niacin treatment of hypercholesterolemia in children. Pediatrics. 1993;92:78-82

157. Clauss S, Wai KM, Kavey RE, Kuehl K. Ezetimibe treatment of pediatric patients with hypercholesterolemia. J Pediatr. 2009;154: 869-872.

158. Rossebo AB, Pedersen TR, Boman K, et al. Intensive lipid lowering with simvastatin and ezetimibe in aortic stenosis. $N$ Engl J Med. 2008;359:1343-1356.

159. Peto R, Emberson J, Landray M, et al. Analyses of cancer data from three Ezetimibe trials. N Engl J Med. 2008;359:1357-1366.

160. Halleck M, Davis HR, Kirschmeier P, et al. An assessment of the carcinogenic potential of ezetimibe using nonclinical data in a weightof-evidence approach. Toxicology. 2009;258:116-120.

161. Steinberger J, Daniels SR, Eckel RH, et al. Progress and challenges in metabolic syndrome in children and adolescents: a scientific statement from the American Heart Association Atherosclerosis, Hypertension, and Obesity in the Young Committee of the Council on Cardiovascular Disease in the Young; Council on Cardiovascular Nursing; and Council on Nutrition, Physical Activity, and Metabolism. Circulation. 2009;119:628-647.

162. Kelley GA, Kelley KS. Aerobic exercise and lipids and lipoproteins in children and adolescents: a meta-analysis of randomized controlled trials. Atherosclerosis. 2007;191:447-453.

163. Feitosa MF, Rice T, Rankinen T, et al; Common genetic and environmental effects on lipid phenotypes: the HERITAGE family study. Hum Hered. 2005;59:34-40.

164. An P, Borecki IB, Rankinen T, et al; Evidence of major genes for plasma HDL, LDL cholesterol and triglyceride levels at baseline and in response to 20 weeks of endurance training: the HERITAGE Family Study. Int J Sports Med. 2005;26:414-419.

165. Pinhas-Hamiel O, Zeitler P. Acute and chronic complications of type 2 diabetes mellitus in children and adolescents. Lancet. 2007;369 1823-1831.

166. Maahs DM, Wadwa RP, Bishop F, et al. Dyslipidemia in youth with diabetes: to treat or not to treat? J Pediatr. 2008;153:458-465.

167. Kershnar AK, Daniels SR, Imperatore G, et al. Lipid abnormalities are prevalent in youth with type 1 and type 2 diabetes: The search for diabetes in youth study. J Pediatr. 2006;149:314-319.

168. McCrindle BW, Urbina EM, Dennison BA, et al. Drug therapy of high-risk lipid abnormalities in children and adolescents: A scientific statement from the American Heart Association Atherosclerosis, Hypertension, and Obesity in Youth Committee, Council of Cardiovascular Disease in the Young, with the Council on Cardiovascular Nursing. Circulation. 2007;115:1948-1967.

169. Oliveira AC, Oliveira AM, Adan LF, et al. C-reactive protein and metabolic syndrome in youth: a strong relationship? Obesity. 2008;16:1094-1098.

170. Schwimmer JB, Pardee PE, Lavine JE, Blumkin AK, Cook S. Cardiovascular risk factors and the metabolic syndrome in pediatric nonalcoholic fatty liver disease. Circulation. 2008;118: 277-283.

171. Pacifico L, Cantisani V, Ricci P, et al. Nonalcoholic fatty liver disease and carotid atherosclerosis in children. Pediatr Res. 2008;63: 423-427.

172. Alisi A, Manco M, Panera N, Nobili V. Association between type two diabetes and non-alcoholic fatty liver disease in youth. Ann Hepatol. 2009;8(Suppl 1):S44-S50.

173. Rodenburg J, Vissers MN, Daniels SR, Wiegman A, Kastelein JJ. Lipid-lowering medications. Pediatr Endocrinol Rev. 2004;2(Suppl)1: $171-180$ 
174. Zdravkovic V, Daneman D, Hamilton J. Presentation and course of type 2 diabetes in youth in a large multi-ethnic city. Diabet Med. 2004;21:1144-1148.

175. Scott CR, Smith J, Cradock MM, Pihoker C. Characteristics of youthonset noninsulin-dependent diabetes mellitus and insulin-dependent diabetes mellitus at diagnosis. Pediatrics. 1997;100:84-91.
176. Flynn JT, Daniels SR. Pharmacologic treatment of hypertension in children and adolescents. J Pediatr. 2006;149:746-754.

177. Laragh JH. Abstract, closing summary, and table of contents for Laragh's 25 lessons in pathophysiology and 12 clinical pearls for treating hypertension. Am J Hypertens. 2001;14:1173-1177.

\section{Publish your work in this journal}

Vascular Health and Risk Management is an international, peerreviewed journal of therapeutics and risk management, focusing on concise rapid reporting of clinical studies on the processes involved in the maintenance of vascular health; the monitoring, prevention and treatment of vascular disease and its sequelae; and the involvement of metabolic disorders, particularly diabetes. This journal is indexed on PubMed Central and MedLine. The manuscript management system is completely online and includes a very quick and fair peer-review system, which is all easy to use. Visit http://www.dovepress.com/ testimonials.php to read real quotes from published authors.

Submit your manuscript here: http://www.dovepress.com/vascular-health-and-risk-management-journal 